\title{
Bazı Dianthus (Caryophyllaceae) Taksonlarının Türkiye'deki Varlığı Üzerine Bir Araştırma
}

\section{A Research on The Presence of Some Dianthus (Caryophyllaceae) Taxa in Turkey}

\author{
Ergin HAMZAOĞLU* ${ }^{* 1, a}$, Murat KOÇ ${ }^{2, b}$ \\ ${ }^{I}$ Gazi Üniversitesi, Gazi Eğitim Fakültesi, Matematik ve Fen Bilimleri Eğitimi Bölümü, 06500, Yenimahalle, Ankara \\ ${ }^{2}$ Ankara Yıldırım Beyazıt Üniversitesi, Halk Sağılığı Enstitüsü, Geleneksel, Tamamlayıcı ve Entegratif Tıp Anabilim Dalı, 06010, \\ Keçiören, Ankara
}

• Geliş tarihi / Received: 15.01.2019 • Düzeltilerek geliş tarihi / Received in revised form: 28.05.2019 • Kabul tarihi / Accepted: 03.06 .2019

\section{$\ddot{O} z$}

Flora of Turkey and the East Aegean Islands adlı esere göre, Dianthus cinnamomeus Sibth. \& Sm., D. schemachensis Schischk. ve D. seguieri Vill. Türkiye'de Karaman, Erzurum ve Ardahan'da yayılış gösterir. Bu illerde çok sayıla floristik çalışma yapılmasına rağmen, söz konusu türlere ait örnekler toplanamamıştır. Bu çalışmada, yazarlarca toplanmış örnekler, herbaryum örnekleri ve sanal herbaryum fotoğrafları birlikte değerlendirilmiştir. Sonuç olarak, $D$. cinnamomeus ve $D$. schemachensis taksonlarının Türkiye'de yayılış göstermediğine ve $D$. seguieri'nin ise varlığının teyide muhtaç (şüpheli) olduğuna karar verilmiştir.

Anahtar kelimeler: Anadolu, Flora, Hatalı teşhis, Karanfil, Şüpheli kayıt

\begin{abstract}
According to Flora of Turkey and the East Aegean Islands, Dianthus cinnamomeus Sibth. \& Sm., D. schemachensis Schischk. and D. seguieri Vill. are distributed in Karaman, Erzurum and Ardahan in Turkey. These species were not found, although many floristic studies were carried out in these provinces. In this study; collected specimens by authors, herbarium specimens and virtual herbarium images were evaluated together. In conclusion, it was decided that D. cinnamomeus and D. schemachensis are not found in Flora of Turkey and the presence of D. seguieri was considered to be doubtful.
\end{abstract}

Keywords: Anatolia, Flora, Incorrect diagnosis, Carnation, Doubtful record

\footnotetext{
*a Ergin HAMZAOĞLU; erginhamzaoglu@yahoo.com; (0535) 391 17 80; orcid.org/0000-0001-6053-6796

${ }^{\mathrm{b}}$ orcid.org/0000-0002-0829-4571
} 


\section{Giriş}

Dünya genelinde yaklaşık 320 tür içeren Dianthus L. (Caryophyllaceae) cinsine ait türlerin büyük bir kısmı Avrupa, Asya ve Kuzey Afrika'da yetişir (Mabberley, 2008). Türkiye Florası'nda, Dianthus cinsi revizyonunda genel olarak Williams (1893)'ın monografi takip edilmiştir (Reeve, 1967). Ayrica Rus Floras1 (Schischkin, 1985) ve Avrupa Floras1 (Tutin ve Walters, 1993) gibi ilgili eserlerden de yararlanılmıştır. Cinsin ülkemiz örnekleri kaleme alınırken, özellikle yerli toplayıciların az olması nedeniyle, betimlemeler genellikle yetersiz örneğe dayanılarak oldukça kısa ve detaysız yazılmıştır. Bu durum türlerin teşhisini güçleştirmiştir. Ayrıca, bazı taksonlarda tip örnekler ve/veya orijinal eserler de görülmemiştir (Reeve, 1967). Bu nedenle büyük bir emeğin ürünü olmasına karşın, söz konusu eserin çok tatmin edici olduğu söylenemez.

Son yıllarda Türkiye ve çevre ülkelerde yapılan bazı çalışmalar, cinsin taksonomik eksikliğini giderici niteliktedir (Rechinger, 1988; Strid, 1997;
Hamzaoğlu vd., 2015; Hamzaoğlu ve Koç, 2018). Bu çalışmada, Türkiye Florası'nda adı geçen bazı Dianthus taksonlarının Türkiye'deki varlığı yeniden değerlendirilmiştir.

\section{Materyal ve Metotlar}

$\mathrm{Bu}$ çalışmanın materyalini Karaman ve Erzurum'dan toplanmış örnekler, herbaryum örnekleri (GAZI, Gazi Üniversitesi herbaryumu) ve sanal herbaryum (E, Edinburgh herbaryumu) fotoğrafları oluşturmaktadır. Bitkilerin betimlemeleri için Türkiye Florası (Reeve, 1967), Kafkasya Floras1 (Grossheim, 1945), Rus Floras1 (Schischkin, 1985) ve Yunanistan Florası (Strid, 1997)'ndan yararlanılmıştır. Habit ve çiçek fotoğraflarının çekiminde Canon EOS 60D dijital kamera kullanılmıştır. Türkiye Florası'nda Dianthus cinnamomeus ve D. schemachensis'in Türkiye'deki varlığına delil olarak gösterilen örnekler ile bunlarla aynı yerlerden toplanmış örneklere ait adres ve etiket bilgileri Tablo 1'de verilmiştir.

Tablo 1. Dianthus cinnamomeus ve $D$. schemachensis'in Türkiye Florası'nda atıf yapılan ve bu çalışma kapsamında toplanan örneklerine ait adres ve etiket bilgileri.

\begin{tabular}{|l|l|l|}
\hline D. cinnamomeus Sibth. \& Sm & Adres ve toplayıcı & Herbaryum \\
\hline $\begin{array}{l}\text { Türkiye Florası'nda atıf yapılan } \\
\text { örneğe ait bilgiler }\end{array}$ & $\begin{array}{l}\text { [Türkiye] In collibus aridis pr. Karaman, Lyconia [Konya], Jun. } \\
1845, \text { Heldreich s.n. }\end{array}$ & $\begin{array}{l}\text { E, E00493169 } \\
\text { foto }\end{array}$ \\
\hline $\begin{array}{l}\text { Bu çalı̧ma kapsamında } \\
\text { toplanan örneğe ait bilgiler }\end{array}$ & $\begin{array}{l}\text { Türkiye. Karaman: Karaman-Seyithasan köyü aras1, 1200 m, } \\
18.6 .2013, \text { Hamzaoğlu 6771 }\end{array}$ & GAZI \\
\hline D. schemachensis Schischk. & Adres ve toplayıcı & Herbaryum \\
\hline $\begin{array}{l}\text { Türkiye Florası'nda atıf yapılan } \\
\text { örneğe ait bilgiler }\end{array}$ & $\begin{array}{l}\text { [Türkiye] Armenia [probably Erzurum], May 1867, Calvert \& } \\
\text { Zohrab s.n. }\end{array}$ & $\begin{array}{l}\text { E, E00493178 } \\
\text { foto }\end{array}$ \\
\hline $\begin{array}{l}\text { Bu çalışma kapsamında } \\
\text { toplanan örneğe ait bilgiler }\end{array}$ & $\begin{array}{l}\text { Türkiye. Erzurum: Pasinler, Demirdöven-Yayla köyleri arası, } \\
\text { 1920 m, 6.7.2013, Hamzaoğlu 6851 }\end{array}$ & GAZI \\
\hline
\end{tabular}

\section{Bulgular ve Tartışma}

\subsection{Dianthus cinnamomeus Sibth. \& Sm., Fl. Graec. Prodr., 1: 287 (1809).}

Türkiye Florası'nda, D. cinnamomeus'un Türkiye'deki varlığı Heldreich'in "Karaman" adresli örneğine dayandırılmıştır (Reeve, 1967). E sanal herbaryumunda "E00493169" barkod numarası ile muhafaza edilen örneğin, yüksek çözünürlüklü fotografi detaylı olarak incelenmiştir (URL-1, 2018). Heldreich'in örnek topladığ 1 popülasyonu tespit etmek amaciyla, Karaman civarında yoğun arazi çalışmaları yapılmış ve Karaman-Seyithasan köyü arasında benzer örnekler bulunmuştur (Tablo 1).
Türkiye Florası'nda $D$. cinnamomeus ve $D$. pallens Sibth. \& Sm. yakın türler olarak yorumlanmıştır. D. cinnamomeus'ta petallerinin çoğunlukla kaliks içinde kalması ve renginin tarçın-kırmızısı (cinnamon-red) olması, bu iki tür arasındaki fark olarak gösterilmiştir (Reeve, 1967). Karaman popülasyonundan toplanan örneklerin incelenmesi sonucunda petalleri tarçınkırmızısı veya kremsi ve kaliksin içinde veya dışında olan bireylere rastlanmıştır (Tablo 1, Şekil 1 ve 2). Bu tespitler, Türkiye Florası'nda kullanılan karakterlerin D. cinnamomeus ile $D$. pallens arasında ayırt edici olarak kullanılamayacağını göstermiştir. 
Yunansitan Florası'na göre; D. cinnamomeus kısır sürgünlü, yaprakları en fazla $30 \mathrm{~mm}$ boyunda, kaliks boyu 13-19(-22) mm, kaliks dişi boyu c.
$4 \mathrm{~mm}$ ve petal ayası boyu $4-8 \mathrm{~mm}$ olan bir türdür (Tablo 2). Ayrica takson, muhtemel bir Yunanistan endemiğidir (Strid, 1997).

Tablo 2. Dianthus cinnamomeus ve D. pallens' in farkl1 ve benzer taksonomik karakterleri.

\begin{tabular}{|l|l|l|}
\hline Karakterler & D. cinnamomeus & D. pallens \\
\hline Gövde boyu & $8-20(-35) \mathrm{cm}$ & $20-50 \mathrm{~cm}$ \\
\hline Gövde tüyü & tüysüz veya bazen altta tüylü & tüysüz \\
\hline Gövde düğüm sayısı & 3-6 adet & $5-7$ adet \\
\hline Gövde yaprağı boyu & en fazla $30 \mathrm{~mm}$ & $30-70 \mathrm{~mm}$ \\
\hline Kisır sürgün yaprakları & var & yok \\
\hline Kaliks pulu sayısı & 4 adet & $4-6$ adet \\
\hline Kaliks pulu x Kaliks oranı & kaliks pulu kaliksin c. $1 / 3$ 'ü kadar & kaliks pulu kaliksin c. 1/3'ü kadar \\
\hline Kaliks boyu ve eni & $13-19(-22) \times 4-6 \mathrm{~mm}$ & $15-31 \times 3.5-5.5 \mathrm{~mm}$ \\
\hline Kaliks dişi boyu & c. $4 \mathrm{~mm}$ & c. $3-6.5 \mathrm{~mm}$ \\
\hline Petal ayası şekli & tersyumurtams & oblong-kuneat veya genişçe kuneat \\
\hline Petal ayası boyu & $4-8 \mathrm{~mm}$ & $8-10 \mathrm{~mm}$ \\
\hline
\end{tabular}

$\mathrm{Bu}$ çalışma kapsamında Karaman civarından toplanan örneklerde ise (Hamzaoğlu 6771, GAZI); kısır sürgün yok, yapraklar 30-70 mm boyunda, kaliks boyu $15-31 \mathrm{~mm}$, kaliks dişi boyu c. 3-6.5 $\mathrm{mm}$ ve petal ayası boyu $8-10 \mathrm{~mm}$ 'dir (Tablo 2). Yunanistan Florası dikkate alınarak incelendiğinde, Karaman örneklerinin D. pallens ile örtüştüğü görülmüştür. Ayrıca Yunanistan Florası'nda yer alan D. cinnamomeus betimlemesinde "petaller çoğunlukla kaliks içinde kalır" şeklinde bir ifade kullanılmamıştır (Strid, 1997). Reeve (1967) tarafindan bir fark olarak ileri sürülen bu karakter, muhtemelen sadece Heldreich'in Karaman'dan topladığı örneğe dayanılarak belirlenmiştir.

Ayrıca, Türkiye Florası'nda D. cinnamomeus'un tip yeri olarak "Laconia [Greece], Asia Minor,
Cyprus \& Byzantium" adresleri verilmiştir (Reeve, 1967). Yunanistan Florası'nda, bu tip adreslerin muhtemelen tümünün hatalı olduğu ve türü tanımlayan Sibthorp'un ilk örnekleri büyük ihtimalle Naxos adasından (Yunanistan) topladığı belirtilmiştir. Karaman örnekleri içinse, türün yayılış alanının dışında bulunduğu ve doğrulanmaya muhtaç olduğu değerlendirmesi yapılmıştır (Strid, 1997). Bu çalışmada Karaman popülasyonunda detaylı inceleme yapılmış ve bunların $D$. pallens olduğuna karar verilmiştir. $D$. pallens, batıda İstanbul, Bilecik ve İzmir'den başlayıp, doğuda Anadolu Çaprazına kadar devam eden geniş bir yayılışa sahiptir (Şekil 3). Bulgular ışığında, D. cinnamomeus türünün ülkemizde yayılış göstermediği ve Türkiye Florası'na hatalı bir değerlendirme sonucu eklendiği sonucuna varılmıştır.

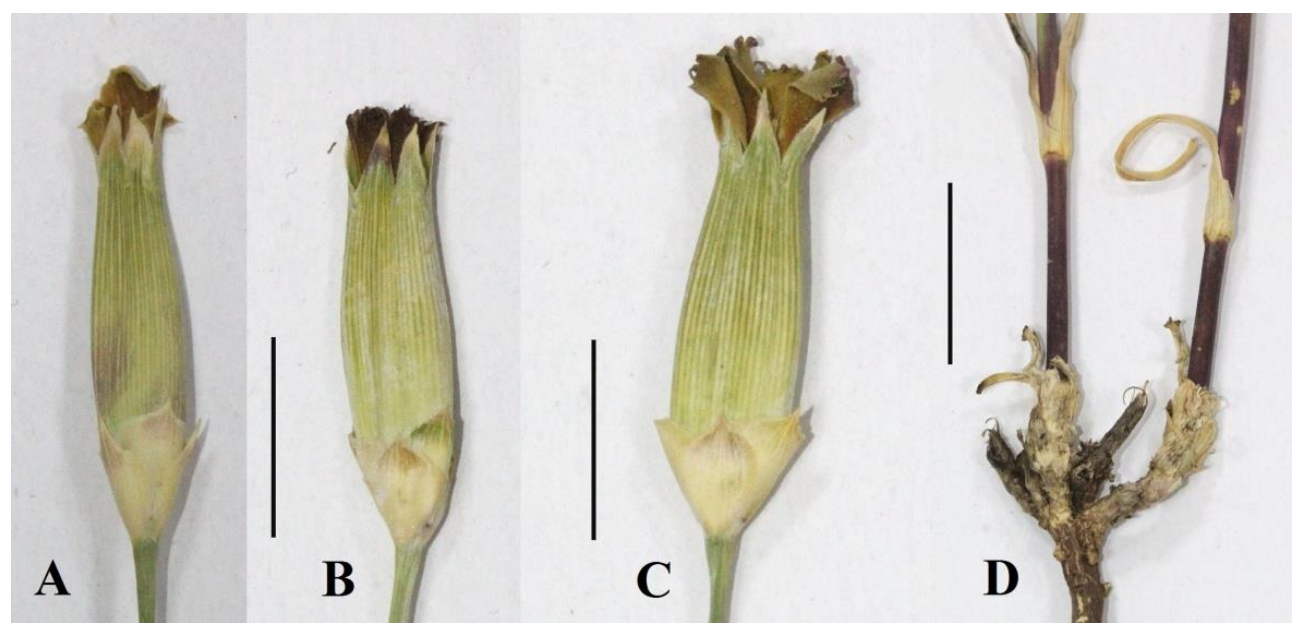

Şekil 1. Dianthus pallens' in Karaman populasyonu (Hamzaoğlu 6771). A- kaliks içinde kremsi petaller, Bkaliks içinde tarçın-kırmızısı petaller, C- kaliks dışında kremsi petaller, D- kısır sürgünü olmayan gövde tabanı (Ölçek: A, B ve C; 1 cm, D; 2 cm). 


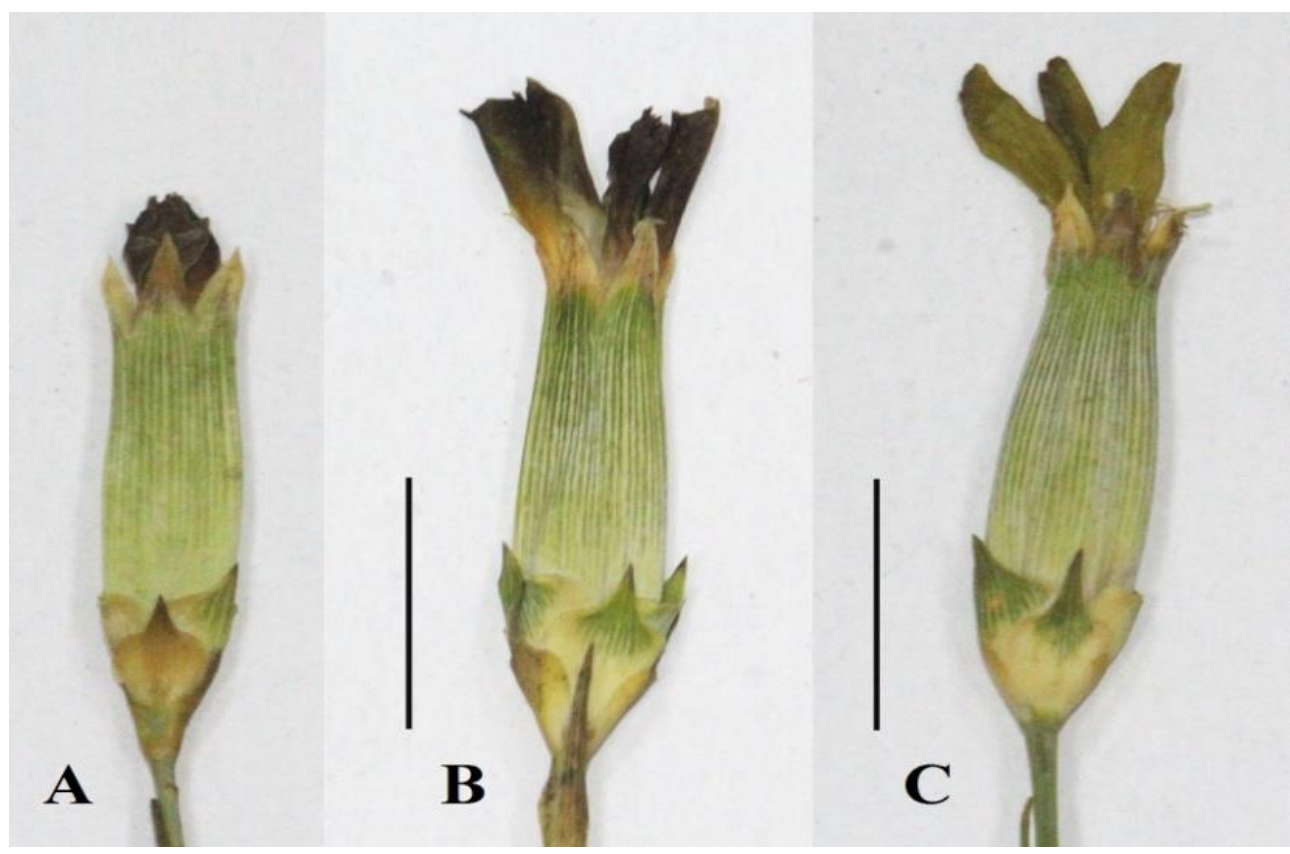

Şekil 2. Dianthus pallens' in İstanbul populasyonu (Hamzaoğlu 6387). A- kaliks içinde tarçın-kırmızısı petaller, B- kaliks dışında tarçın-kırmızısı petaller $\mathbf{C}$ - kaliks dışında kremsi petaller (Ölçek; $1 \mathrm{~cm}$ ).

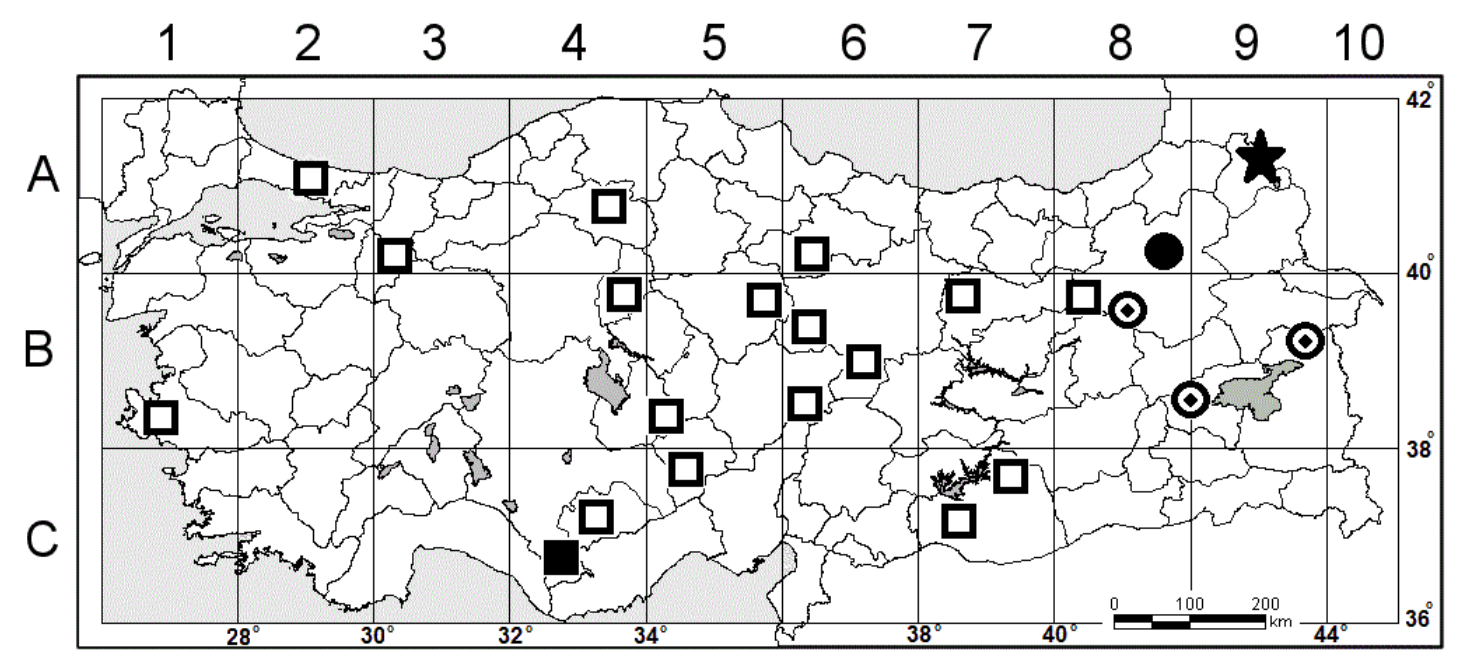

Şekil 3. Dianthus pallens $(\boldsymbol{\square})$, D. plumbeus $(\odot)$ ve $D$. seguieri $(\star)^{\prime}$ 'nin Türkiye'deki bilinen veya muhtemel yayılış1 [Türkiye Florası'nda $D$. cinnamomeus olarak atıf yapılan $D$. pallens $(\mathbf{\square})$ ve $D$. schemachensis olarak atıf yapılan D. plumbeus $(\bullet)$ örnekleri].

3.2 Dianthus schemachensis Schischk., Trud. Geo. Obsl. Pastb. S.S.R. Azerb., Baku, Ser. A(7): 90 (1931).

Taksonun Türkiye Florası'ndaki varlığı Calvert ve Zohrab'ın "Armenia (probably Erzurum)" adresli örneğine dayandırılmıştır (Reeve, 1967). Örneğin E sanal herbaryumunda bulunan yüksek çözünürlüklü fotografı detaylı olarak incelenmiştir (URL-1, 2018). Üzerinde "E00493178" barkod numaras1 bulunan örnek, Calvert ve Zohrab tarafindan D. longicaulis Ten. olarak yanlış teşhis edilmiştir. D. longicaulis Hırvatistan, İtalya,
Fransa ve Ispanya'da yayılış gösteren bir taksondur (Tutin ve Walters, 1993). Bu örnek Reeve (1967) tarafindan D. schemachensis olarak değerlendirilmiştir (Tablo 1).

Erzurum civarında yapılan arazi çalışmasında, "Pasinler, Demirdöven-Yayla köyleri arası" adresinden bazı ilginç Dianthus örnekleri toplanmıştır (Tablo 1). Türkiye Florası dikkate alınarak incelendiğinde, bunların Reeve (1967) tarafindan D. schemachensis olarak değerlendirilen örnekle aynı olduğu görülmüştür (Şekil 4). 


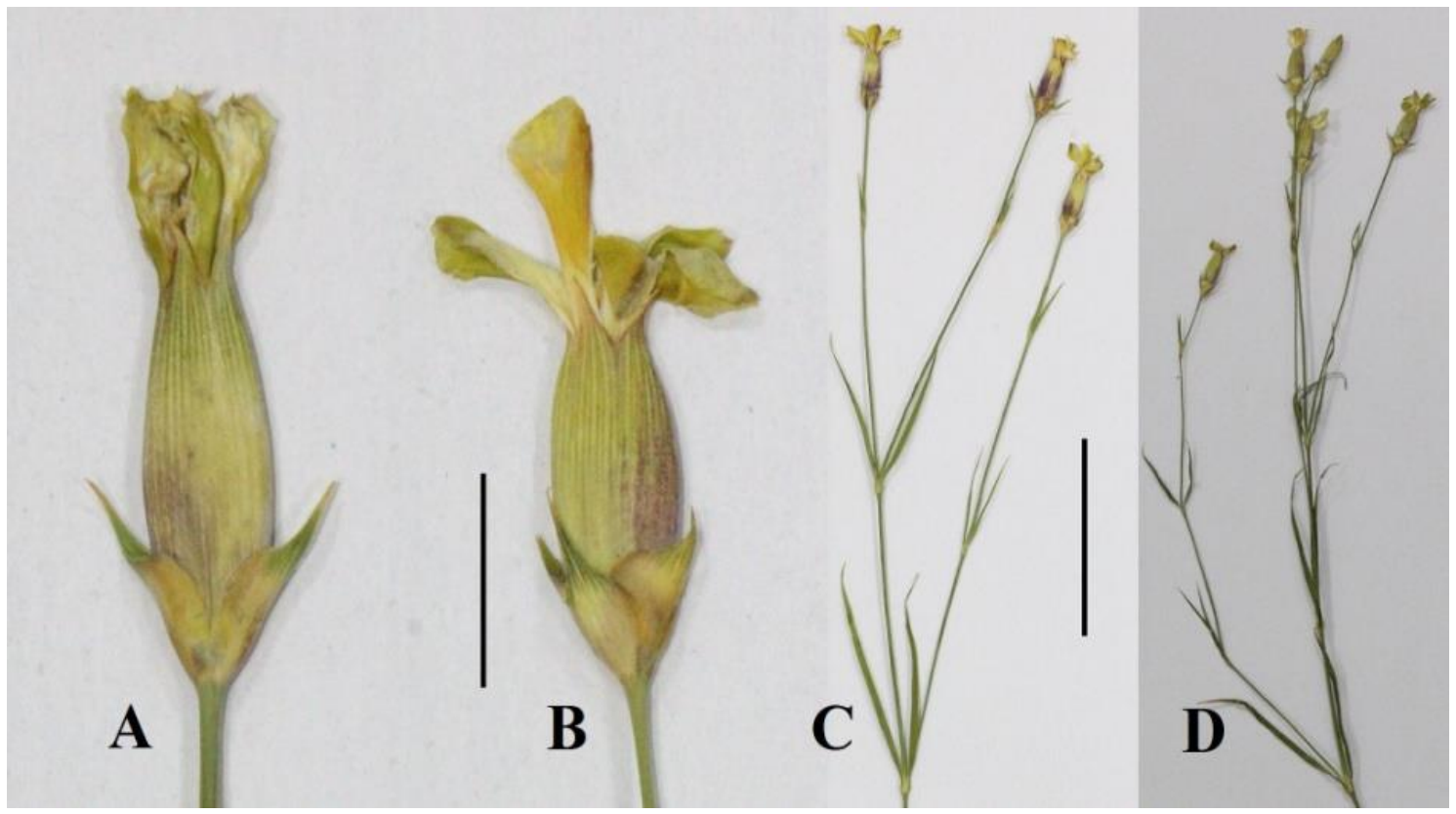

Şekil 4. Dianthus plumbeus' in Erzurum populasyonu (Hamzaoğlu 6851). A ve B- kaliks pulu 2 ve 4 adet, petal kremsi, C ve D- 3 veya 5 çiçekli gövde (Ölçek: A ve B; $1 \mathrm{~cm}, \mathrm{C}$ ve D; $5 \mathrm{~cm}$ ).

Rus Florası'na (Schischkin, 1985) göre; bir Azerbaycan endemiği olan D. schemachensis'te gövdeler 5-18 cm boyunda ve genellikle tek çiçekli, yapraklar 2-3 $\mathrm{cm}$ boyunda, kaliks pulları 4 adet ve 5-6 mm boyunda, petal ayas $6-8 \mathrm{~mm}$ boyunda ve koyu mor renktedir (Tablo 3). Erzurum'dan toplanan örneklerde ise; gövdeler $35-55 \mathrm{~cm}$ boyunda ve 3-5(-7)-çiçekli, yapraklar $5-9 \mathrm{~cm}$ boyunda, kaliks pulları $2-4$ adet ve $7-15$ mm boyunda, petal ayas $9-13 \mathrm{~mm}$ boyunda ve kremsi beyaz renktedir (Tablo 3, Şekil 4). Bu bulgular 1şığında; Reeve (1967) tarafından $D$. schemachensis olarak değerlendirilen "Calvert ve
Zohrab" örneğinin D. plumbeus Schischk. olduğuna, D. schemachensis türünün Türkiye'de yayılış göstermediğine ve floraya hatalı bir değerlendirme sonucu eklendiğine karar verilmiştir. D. plumbeus Anadolu Çaprazının doğusunda Erzurum, Bitlis ve Van civarlarında yayılış gösteren bir Türkiye endemiğidir (Şekil 3).

Taksonun Türkiye Florası'ndaki varlığı, Kafkasya Floras1 (Grossheim, 1945) adlı eserin 3. cildinde yer alan 327 nolu haritaya dayanmaktadır. Bu haritada Grossheim, Dianthus discolor Sm.'un yayılışını vermiştir (Şekil 5).

Tablo 3. Dianthus schemachensis ve D. plumbeus'un farklı ve benzer taksonomik karakterleri.

\begin{tabular}{|l|l|l|}
\hline Karakterler & D. schemachensis & D. plumbeus \\
\hline Gövde boyu & $5-18 \mathrm{~cm}$ & $35-55 \mathrm{~cm}$ \\
\hline Gövde tüyü & tüysüz veya bazen altta tüylü & tüysüz \\
\hline Gövde çiçek sayıs1 & genellikle tek çiçekli & $3-5(-7)$-çiçekli \\
\hline Gövde düğümarası boyu & c. $1 \mathrm{~cm}$ & $4-7 \mathrm{~cm}$ \\
\hline Gövde yaprağı boyu ve eni & $20-30 \times 1-3 \mathrm{~mm}$ & $50-90 \times 1.5-2.5 \mathrm{~mm}$ \\
\hline Kaliks pulu sayısı & 4 adet & $2-4$ adet \\
\hline Kaliks pulu boyu & $5-6 \mathrm{~mm}$ & $7-15 \mathrm{~mm}$ \\
\hline Kaliks şekli & oblong, silindirik & mızraks1 \\
\hline Kaliks boyu ve eni & $21-30 \times 5-6 \mathrm{~mm}$ & $17-25 \times 4-6 \mathrm{~mm}$ \\
\hline Kaliks dişi şekli & mizraks1 & geniş üçgensi \\
\hline Petal ayası şekli & geniş yumurtamsı veya yuvarlağıms1 & tersyumurtams1 \\
\hline Petal ayası boyu ve eni & $6-8 \times 5 \mathrm{~mm}$ & $9-13 \times 5-8 \mathrm{~mm}$ \\
\hline Petal ayası rengi & koyu mor & kremsi beyaz \\
\hline
\end{tabular}




\subsection{Dianthus seguieri Vill., Prosp. Hist. Pl. Dauphiné, 48 (1779).}

D. discolor Türkiye Florası'nda D. seguieri altında sinonim yapıldığ 1 için, taksonun ülkemizde varlığından bahsedilmektedir (Reeve, 1967). Rus Florası'nda D. discolor'un (D. seguieri) habitat bilgisi olarak "Caucasian Mountains, alpine and subalpine meadows, clearings, and mountain woods" yazılmıştır (Schischkin, 1985). Dianthus cinsinin Doğu ve Kuzeydoğu Anadolu'da yayılış gösteren taksonları üzerine yapılan taksonomik çalışmada, D. seguieri (D. discolor) türüne ait örneklerin toplanamadığı belirtilmiştir (Dalc1, 1986).

Kafkasya Florası'nda verilen $D$. discolor (D. seguieri) türüne ait yayılış haritasında Türkiye siyasi sınırları yoktur. Bu nedenle, türün varlığını gösteren noktanın Türkiye içinde olup-olmadığ 1 belirgin değildir (Grossheim, 1945). Güncel ve benzer ölçekli haritalar dikkate alınarak, Grossheim'ın 327 numaralı haritası dikkatli bir şekilde incelenmiş ve yorumlanmıştır. Yapılan değerlendirme sonucu, türün Ardahan ili ÇıldırDamal-Posof ilçeleri arasında bir yerde olabileceği sonucuna varılmıştır (Şekil 5). Bu çıkarımdan sonra, gerek tespit edilen tahmini alan ve gerekse Gürcistan sınırına yakın uygun alanlar (alpin ve subalpin çayırlar) detaylı olarak taranmış, ancak maalesef türe ait örnek bulunamamıştır.

D. discolor'un (D. seguieri) Rus Florası'nda verilen betimlemesi incelendiğinde, Türkiye Florası'nda yer alan D. masmenaeus Boiss. var. glabrescens Boiss.'e habit olarak benzediği görülür. Ancak D. discolor'da (D. seguieri) kaliks 6-7 mm eninde, petal c. $30 \mathrm{~mm}$ boyunda ve petal ayas1 $15 \mathrm{~mm}$ enindedir (Schischkin, 1985). Oysaki D. masmenaeus var. glabrescens'te kaliks 2-3.5 $\mathrm{mm}$ eninde, petal boyu daha kisa ve eni daha dardir (Reeve, 1967). Bu nedenle Grossheim tarafindan tespit edilen örneğin $D$. masmenaeus var. glabrescens'e ait olma ihtimali oldukça zayıftır. Bu durumda iki ihtimal vardır; birincisi Kafkasya Florası'ndaki 327 nolu haritada "ÇıldırDamal-Posof" civarına koyulmuş işaretin, gerçekte olması gereken yerden biraz daha batıda olmasıdır. Zira ilgili harita incelendiğinde, haritanın oldukça küçük olduğu ve $D$. discolor'un (D. seguieri) sınırımıza çok yakın yerlerde bulunduğu rahatlıkla görülmektedir (Şekil 5). İkinci ihtimal ise; türün Türkiye'de bulunduğu, ancak yapılan tüm çalışmalara rağmen henüz tespit edilememiş olmasıdır (Dalc1, 1986; Ocakverdi, 1994, 2001). Sonuç olarak; ilgili literatürler, habitat benzerliği ve yayılış alanı dikkate alınarak türün Türkiye'deki varlığının şüpheli olduğuna karar verilmiştir. Hâlihazırda, toplanmış örneği olmamasına karşın, türün Türkiye'de bulunma ihtimalinin yüksek olduğu düşünülmektedir.

\section{İncelenen İlave Örnekler}

Dianthus pallens - Türkiye. A2 İstanbul: Üsküdar, Büyük Çamlıca, Kısıklı ile zirve arası, 8.7.1971, Demiriz \& Özhatay 384 (ISTO); Kartal, Aydos Dağı, verici civarı, 485 m, 28.6.2012, orman açıklığı, Hamzaoğlu 6387 (GAZI); A4 Çankırı: Korgun-Ilgaz arası, 950 m, Quercus sp. orman1, 19.7.1993, A.A.Dönmez 3570 (HUB); A6 Tokat: Artova-Aktaş arası, Sineburnu Tepesi, c. 1300 m, Quercus sp. orman1, 16.7.1979, R.İlarslan 712 (ANK; ISTO); B1: [İzmir] In Asia Minor prope Smyrnam, Sipthorp s.n.; B2 Bilecik: Kandilli, 1890 (Hb. Post); B4 Kirıkkale: Keskin, mezarlık içi, 1110 m, 11.7.2013, Hamzaoğlu 6855 (GAZI); B5 Yozgat: Akdağmadeni, GemerekKızılcaova arası, $1670 \mathrm{~m}$, orman açıklığ 1 , 21.8.2013, Hamzaoğlu 6995 (GAZI); Aksaray: Güzelyurt, Ihlara köyü, Ihlara Vadisi girişi civarı, 1200-1300 m, 26.5.2007, Hamzaoğlu 4568 (GAZI); B6 Kayseri: Tomarza, Arslantaş köyü yakınları, 1800 m, 12.7.2012, Quercus açıklığ1, Hamzaoğlu 6475 (GAZI); Sivas: Şarkışla batısı, 1510 m, 17.7.2010, jipsli tepeler, Hamzaoğlu 5869 (GAZI); B7 Erzincan: Refahiye-Gölova arası, 1585 m, Quercus açıklı̆̆ı, 1.7.2013, Hamzaoğlu 6784 (GAZI); B8 Erzincan: TercanAşkale arası, Yakacık köyü çıkışı, kayalık otlu yamaçlar, 1570 m, 2.7.2013, Hamzaoğlu 6787 (GAZI); C4 Karaman: Bucakkışla-Ermenek arası, 1260 m, 27.7.2012, Quercus açıklığı, Hamzaoğlu 6536 (GAZI); C5 Niğde: Fesleğen köyü kuzeyi, Andırmusa Dağı etekleri, 1800 m, 7.7.2012, kayalıklar, Hamzaoğlu 6417 (GAZI); C7 Şanlıurfa: Şanlıurfa-Gaziantep arası otoyolu, c. 20. km, $820 \mathrm{~m}, 25.5 .2013$, taşlı yamaçlar, Hamzaoğlu 6692 (GAZI). Dianthus plumbeus Türkiye. A8 Erzurum: Çat yolu, Taşligüney köyünün $2 \mathrm{~km}$ güneybatıs1, 2000-2050 m, 4.8.1975, M.Dalcl 390 (OMUB); [Bitlis] In querceto supra pag. Czuchur-Norschen [Güroymak], c. $1400 \mathrm{~m}, 14.5 .1916$, Schischkin s.n. (LE); B9 Van: Muradiye, Selale civarı, c. 1900 m, 3.6.1986, Ö.Seçmen 3815 (EGE).

\section{Teşekkür}

Bu çalışmanın materyalleri, TÜBİTAK tarafindan desteklenen KBAG-111T873 kodlu proje kapsamında toplanmıştır. Desteklerinden dolayı TÜBİTAK'a teşekkür ederiz. 


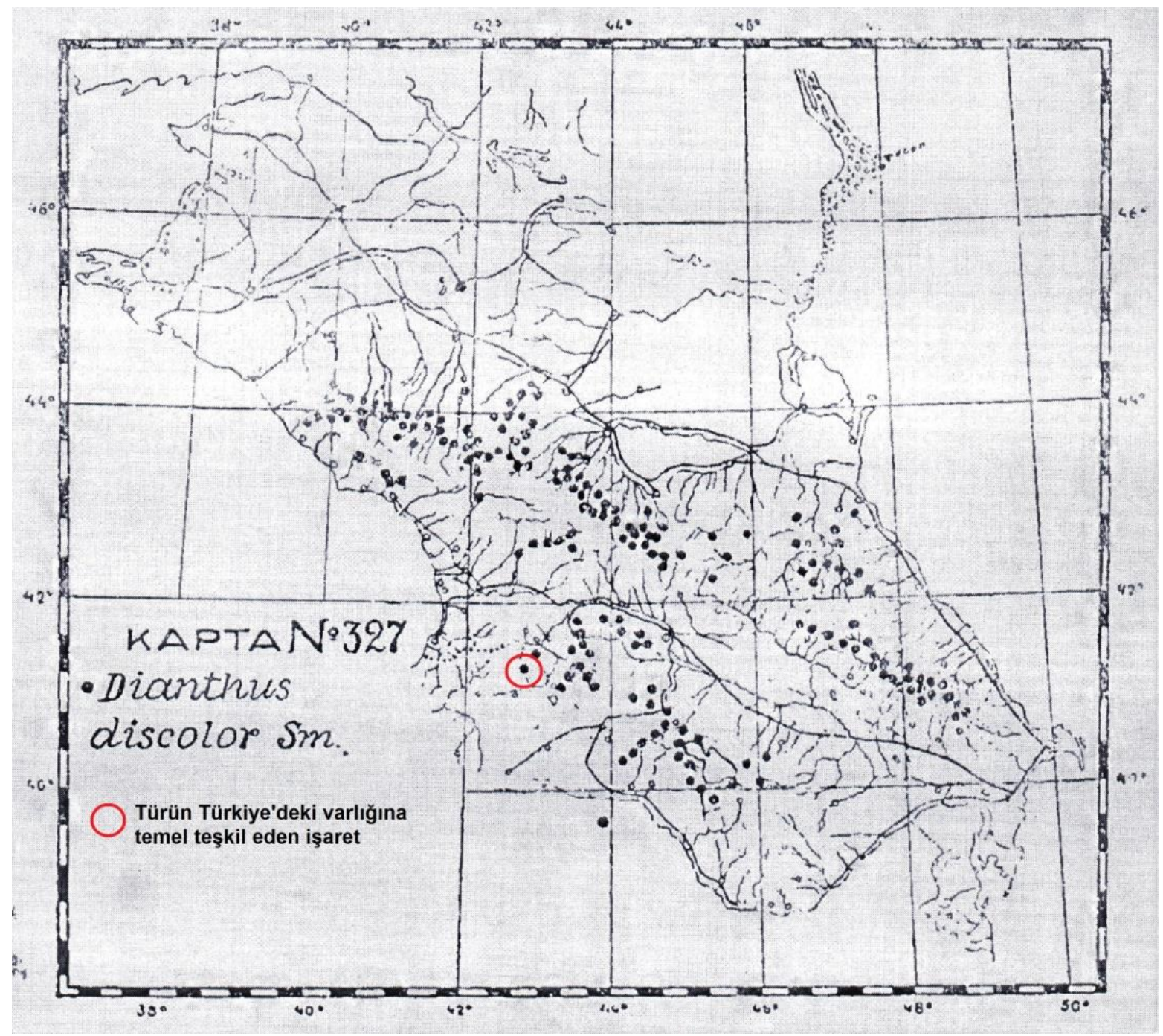

Şekil 5. Kafkasya Florası'nda Dianthus discolor için verilen yayılış haritası (Grossheim, 1945).

\section{Kaynaklar}

Dalc1, M., 1986. Morphological studies and new synonyms of some species in Dianthus L. DOĞA Turkish Journal of Biology (Botany), 10(2), 138-159.

Grossheim, A.A., 1945. Flora Kavkaza. Akademiia Nauk SSSR, Moscow, Vol. 3, 278-295pp.

Hamzaoğlu, E. ve Koç, M., 2018. Presence of Dianthus glutinosus in Turkey and new variety of this species. Biological Diversity and Conservation, 11(3), 149-152.

Hamzaoğlu, E., Koç, M., Büyük, İ., Aksoy, A. ve Soydam Aydın, S., 2015. Presence of Dianthus roseoluteus Velen. (Caryophyllaceae) in Turkey and a new species: Dianthus macroflorus Hamzaoğlu. Systematic Botany, 40(1), 208-213.

Mabberley, D.J., 2008. Mabberley's Plant-book: a portable dictionary of plants, their classification and uses. Cambridge University Press, Cambridge, third edition, 1021p.
Ocakverdi, H., 1994. Akyaka, Arpaçay, Melikköy ve Değirmenköprüköy Yaylaları (Kars) ile Sovyet sınırı arasında kalan bölgenin bitki sosyolojisi ve ekolojisi yönünden araştırılması. Turkish Journal of Botany, 18(4), 245-265.

Ocakverdi, H., 2001. Flora of the Mount Kisir (Kars and Ardahan) and nearest environs. Turkish Journal of Botany, 25(5), 311-234.

Rechinger, K.H., 1988. Dianthus L. (Flora Iranica, Akademische Druck-u Verlagsanstalt, Graz: Ed. Rechinger, K.H.) Caryophyllaceae II, 128188 pp.

Reeve, H., 1967. Dianthus L. (Flora of Turkey and the East Aegean Islands, Edinburgh University Press, Edinburgh: Ed. Davis, P.H.) Vol. 2, 99$131 \mathrm{pp}$.

Schischkin, B.K., 1985. Dianthus L. (Flora of the U.S.S.R., Bishen Singh Mahendra Pal Singh \& Koeltz Scientific Books, Dehra Dun: Ed. Schischkin, B.K.) Vol. 6, 611-654pp. 
Strid, A., 1997. Dianthus L. (Flora Hellenica, Koeltz Scientific Books, Königstein: Eds. Strid, A. ve Tan, K.) Vol. 1, 343-372pp.

Tutin, T.G. ve Walters, S.M., 1993. Dianthus L. (Flora Europaea, Cambridge University Press, Cambridge: Eds. Tutin, T.G., Burges, N.A., Edmondson, J.R., Heywood, V.H., Chater,
A.O., Moore, D.M., Akeroyd, J.R., Valentine, D.H., Mill, R.R., Walters, S.M., Webb, D.A. ve Newton, M.E.) Vol. 1, 227-246pp.

URL-1, http://data.rbge.org.uk/herb. 25.12.2018.

Williams, F.N., 1893. A monograph of the genus Dianthus. Botanical Journal of the Linnean Society, 29(203), 346-378. 